\title{
Understanding and Responding to the Unique Needs and Challenges Facing Adjunct Faculty: A Longitudinal Study
}

\author{
Kimberly Buch, Heather McCullough and Laura Tamberelli \\ University of North Carolina Charlotte
}

\begin{abstract}
This study reports the results of a longitudinal study of adjunct faculty at a large research-intensive institution. A needs assessment found that adjunct faculty felt isolated and disconnected from their departments and colleagues, and reported a lack of formal and informal supports needed for success in their instructional roles. These findings guided the development and campus-wide implementation of adjunct-specific programming and resources. A program evaluation found improvements in adjunct faculty perceptions of support as well as directions for future programming and development opportunities.
\end{abstract}

Keywords: non-tenure-track faculty; adjunct professors; professional development; part-time instructors.

\section{Introduction}

Non-tenure-track faculty are the largest and fastest growing segment of the American professoriate. Recent data (Kezar \& Maxey, 2014) indicate that over $70 \%$ of all faculty across 2 - and 4-year institutions work off the tenure track, a trend that has been on the rise for the past two decades. Non-tenure-track faculty also tend to carry heavier teaching loads and teach larger course sections than tenure-track faculty (AAUP, 2013). Clearly, this "new faculty majority" (Kezar \& Sam, 2010) is impacting a growing percentage of American college students. This reality raises many important questions in need of exploration: Who are non-tenure-track faculty? What are their unique needs and challenges? What types of targeted resources and professional development opportunities are most responsive to these needs and challenges? How do adjunct faculty respond to institutional efforts to deliver targeted resources and programming? We attempted to address these questions with a three-year study of adjunct faculty at a large, research-intensive public university. 
Who are Non-Tenure-Track Faculty? This diverse group of faculty presents definitional challenges as researchers have counted over 50 terms used to describe them (Kezar \& Sam, 2010). The American Association of University professors (AAUP) uses the term "contingent faculty" because it signals the tenuous, contractual relationship between these faculty and their academic institutions, while the American Society for Higher Education (ASHE) prefers the term non-tenure track (Kezar \& Maxey, 2014). Both terms (contingent and non-tenure track) are widely accepted umbrella terms that include part- and fulltime faculty who are appointed off the tenure track, ranging from adjuncts (typically part-time and compensated on a per-course basis) to lecturers (typically full-time and paid a salary). Both the AAUP and ASHE argue that it is important for researchers and practitioners to be aware of and acknowledge the heterogeneity within this group of faculty (Kezar \& Maxey, 2014).

Of the dimensions on which non-tenure-track faculty differ, perhaps that with the greatest bearing on their professional development needs is the part-time vs. full-time dimension. First, part-time (here referred to as adjunct) faculty are the fastest growing segment of the professoriate, and constitute an estimated 51.2\% of instructional faculty in American higher education (Kezar \& Maxey, 2014). Sheer numbers will require institutions to leverage the strengths and manage the challenges of this large and rapidly growing group of faculty. Thus, this study focused exclusively on part-time adjunct faculty and intentionally excluded fulltime lecturers, even though the latter are non-tenure-track faculty whose jobs also differ significantly from traditional tenure-track faculty.

What are the Unique Challenges and Professional Needs of Adjunct Faculty? Although there is a relative paucity of research examining adjunct faculty, there is much anecdotal evidence that adjunct faculty face challenges unique to their part-time status. One challenge is a general lack of understanding about adjunct faculty-e.g., it is widely assumed that adjunct faculty work part-time completely by choice and that they often have other employment (and benefits!) outside of the university. However, many adjunct faculty are working part-time because they cannot obtain a full-time teaching position (Kezar \& Maxey, 2014), and the majority of part-time adjunct faculty do not have professional careers outside of academe (AAUP, 2013). This exacerbates the problems inherent in their place at the bottom of the "multi-tier academic labor structure" (AAUP, 2013). This multi-tiered system that is increasingly bottom-heavy, is clearly inequitable in terms of salary, benefits, and job security. The median pay per course for adjunct faculty is $\$ 2,700$ (Kingkade, 2013), and part-time faculty are estimated to make $65 \%$ less than full-time faculty for the same work (Levin \& Hernandez, 2014). They face working conditions that often differ dramatically from those of full-time faculty, including fewer instructional resources, less institutional support, limited interaction with colleagues, and little input into faculty governance (Buch \& McCullough, 2016; Kezar, 2012; Levin \& Hernandez, 2014).

Based on the above, it is not surprising that adjunct faculty are much more likely than full-time faculty to experience feelings of isolation, lack of connectedness to 
the academic community, and perceptions of marginalization (e.g., Buch \& McCullough, 2016; Fagan-Wilen, Springer, Ambrosino, \& White, 2007; Forbes, Hickey, White, 2010; Levin \& Hernandez, 2014; Webb, Wong, \& Hubball, 2013). Other researchers have noted the relationship between these experiences of isolation and the job satisfaction and turnover rates among part-time faculty (e.g., Hoyt, 2012; Meixner \& Kruck, 2010). It seems clear that these realities have important implications, including concerns about workplace fairness and equity and threats to the instructional mission of post-secondary institutions - after all "faculty working conditions are student learning conditions" (New Faculty Majority, 2015). Given the changing state of the professoriate, and its tremendous implications for higher education, increased attention to adjunct faculty is urgently needed (Kezar \& Sam, 2010; Levin \& Hernandez, 2014).

\section{Methods}

Phase 1: Needs Assessment. This study took place at a large, public researchintensive institution and was initiated by faculty and staff in The Center for Teaching and Learning (CTL). The study emerged from an effort to better understand the needs of the adjunct faculty so that institutional supports and professional development opportunities could be developed in direct response to these needs. As described above, the faculty population of interest was the group most typically referred to in the literature as "adjunct faculty," which we define as non-tenure-track faculty working part-time and compensated on a percourse basis. Although adjunct faculty at this institution can and do participate in all instructional and professional development opportunities provided by the CTL, we wanted to ensure programming and support that was aligned with the unique needs of adjunct faculty.

Data obtained from the Office of Institutional Research at the beginning of the study indicated there were 398 adjunct faculty (approximately one-third of all faculty), who together taught 26,992 students in 730 courses, for a total of 2,094 course-hours. A brief electronic survey was developed by the researchers and sent via university email to 390 adjunct faculty. The survey contained five openended questions asking about major challenges facing adjunct faculty; types of professional support provided them in their adjunct role; awareness of professional development support available from the CTL; types of additional support/resources/ programming they would find beneficial; and factors that would encourage them to participate in professional development opportunities. Responses were received from 98 faculty, a $25 \%$ response rate. A qualitative analysis of responses identified a gap between current levels of support received and desired levels of support, as well as suggestions for closing this gap based on the reported realities and challenges of adjunct faculty.

Specifically, results indicated that fewer than $10 \%$ of respondents were satisfied with the level of support they received from the institution. Approximately 25\% indicated they received no support from their academic departments, or support only when they seek it out or ask for assistance. Of the $75 \%$ reporting they receive professional support, the type of support varied. The major form of support reported was administrative (secretarial, office space and supplies, 
email access, etc.); for many, this was the only type of support received. Fewer than a quarter of respondents reported some type of pedagogical/ instructional support from their units (e.g., shared syllabi, teaching plans and ideas, advice and teaching suggestions, drop-in consultations, feedback on teaching materials, etc.). The majority of reported support was informal (ad hoc, on request), with fewer than $25 \%$ participating in formal support from administrators, peers, or mentors. Sources of support varied, with about $10 \%$ provided by department chairs; another $10 \%$ reported support from colleagues, and a smaller percentage reported support from a mentor or "lead instructor."

Another line of questioning asked about the instructional and professional development opportunities offered by the CTL. Over one third of respondents had not participated in any resources or programming by the CTL. Over one third of respondents had participated in one or more technology workshops (e.g., Moodle, Mahara, Clickers) conducted by the CTL; almost that many reported use of the online CTL teaching tutorials and guides. These findings are consistent with the literature in several ways. Studies consistently reveal a gap between the desire of non-tenure-track faculty to participate in professional development activities and the institutional provision of opportunities to do so (Fagan-Wilen, Springer, Ambrosino, \& White, 2006; Gappa \& Leslie, 1993; Hoyt, 2012; Kezar \& Sam, 2010).

The next open-ended question asked respondents to identify specific types of supports not received which they would find most beneficial. Again, the responses varied greatly but two major themes emerged from content analysis: pedagogical/instructional support and basic orientation support. Almost $40 \%$ of comments were related to teaching and pedagogy, ranging from use of the LMS (learning management system) to attendance policies, to pedagogical strategies, to online teaching, to classroom management. The other theme pertained to more basic, "onboarding" types of supports, such as accessing campus resources, policies and procedures, human resources, parking, textbook adoptions, etc. Both of these themes would be instrumental in the design of our adjunct initiatives, as described in stage 2 below.

The needs assessment also asked faculty to report (via write-in format) the major challenges they face as adjunct faculty. While a wide range of challenges were reported, the overwhelming theme to emerge from content analysis was a sense of isolation and disconnectedness from their departments and colleagues. Comments related to this theme were reported by almost a third of respondents $(32 \%)$. The following quotes are illustrative of this theme:

- "I have little contact with my department."

- "It requires a lot of extra effort to stay connected with colleagues."

- "It is entirely an independent enterprise."

- "Lack of interaction between adjunct and full-time faculty."

- "Being an island. Being unaware of the larger picture."

- "Isolation."

- "No real support." 
- "Feeling marginalized and excluded."

- "You constantly feel on the run and out of the loop."

The next most frequently reported challenge loaded on the theme of "lack of training or orientation," which was mentioned by $24 \%$ of respondents, followed by juggling multiple job demands (9\%); poor pay and benefits $(5 \%)$; lack of contracts $(4 \%)$; lack of space $(4 \%)$; and cost of parking (3\%). Only $11 \%$ of respondents either left the item blank or wrote in that they currently faced no challenges. (See Table 4 below for a comparison of challenges reported in the needs assessment and how they changed in the post-survey.)

Another line of questioning in the needs assessment asked respondents what would encourage them to participate in the support and development opportunities that currently are or will be offered in the future. This was important because the literature suggests that participation rates in development opportunities and institutional supports among part-time faculty are modest, ranging from $48 \%$ to $56 \%$ to $63 \%$ (Hoyt, 2012). As shown in Table 1, the following themes emerged from responses to this question: 1) timing of offerings; 2) incentives to participate; 3) awareness of offerings; 4) format of offerings; and 5) usefulness of offerings. Clearly, the first of these is a simple matter of better communication among units, the CTL, and adjuncts. The others are more important as considerations in program design, and contributed greatly to our programming and design decisions, as described below.

Table 1. Needs Assessment: Thematic Results and Direct Quotes of Respondents What Would Encourage you to Participate in Professional Development Opportunities?

Timing of Offerings

"Evenings; Afternoons; Early mornings; Multiple repeat offerings to accommodate diverse schedules;"

Incentives to Participate

"Payment/stipend; Recognition by department; Certificates of Achievement; Make it worth my time; Not having to pay for parking to attend; Some kind of monetary incentive; Current pay level not sufficient to invest more time"

Awareness of Offerings

"Access to a training schedule at the start of the semester; Better advertising of opportunities and recurring each semester; A monthly calendar; Knowing about opportunities in advance; Overview of opportunities and timely notice; Reminders"

Usefulness of Offerings

"Anything that would benefit my students; Knowing they will positively affect my students' learning; Relevant topics; The promise of practical training and classroom-ready methods; Meaningful and directly aligned to what I teach; A course specifically designed for adjuncts"

Format of Offerings

"Digital; Online; Remote Access; Face-to-face if opportunity to meet other

adjuncts" 
Phase 2: Institutional Response to Adjunct Needs. The needs assessment provided a wealth of information for designing targeted adjunct resources and programming. First, findings on the types and sources of support-both received and desired-identified a strong need for institutional-wide, formal supports in two major areas: a general adjunct orientation and instructional/pedagogical support. Findings about the high level of isolation and disconnectedness suggested a strong need for some type of face-to-face programming or opportunities for adjunct interactions, yet scheduling challenges suggested a concurrent need for online, on-demand offerings. Findings also suggested that adjunct faculty need to be compensated for their time investments in professional development activities. In response to the needs assessment results, the university developed a range of support and development opportunities for adjunct faculty. In designing professional development opportunities and resources to be responsive to these findings, we also tried to be cognizant of the heterogeneity of the adjunct community, as recommended by Kezar and Maxey (2014) and others. Each of the initiatives designed and implemented by the institution within a year of the needs assessment is described below.

1. "Adjuncts-Only" online resources. In the absence of any centralized orientation for new adjuncts, and with a quarter of adjuncts reporting they receive no support from the departments that hire them, there was a clear need for a university-wide welcome and orientation program for new hires. Adjuncts' preference for on-demand resources and timely, targeted and relevant information provision confirmed beliefs that the program should be developed and delivered via the University's learning management system (LMS) at the time, Moodle 2. Another advantage of this design choice was to provide adjuncts the opportunity to see the LMS from the perspective of their future students. The goal of the orientation was to welcome new adjunct faculty to the institution and to equip (new and returning) adjunct faculty with the information needed to be successful instructors and satisfied employees. It was designed just as one of their courses may be: introduction, lessons with additional materials, and quizzes. The lessons built upon each other chronologically from becoming an adjunct through course design and professional development, as follows: 1) Getting Started; 2) Policies \& Guidelines; 3) Classroom Guidance; 4) Campus Resources. Beginning with a welcome from the Provost, the self-guided modules can be completed in order or as needed by each user. Completion of the modules is optional but the goal is for each new hire to be directed to the program by their hiring unit and encouraged to use it as a getting-started guide and as a departure point for seeking additional information.

The online orientation went live to all adjuncts (new and returning) in June 2015. From June 2015 through August 2016, the orientation was hosted exclusively in Moodle 2 and was accessed by 274 faculty members. During Summer 2016, the University rolled out a new LMS (Canvas) and adjunct orientation went live in Canvas by the beginning of that academic year. During the first semester in use, 
it was accessed by over 205 faculty, had greater than 5,000 pages views, and over 130 quiz submissions.

Our second online adjunct resource to follow the needs assessment was an adjunct website (adjunct.uncc.edu), designed as a "one-stop shop" for adjunct faculty. This website contains much of the same content as the orientation but is designed with quick reference in mind. As a public-facing website, it provides general information to prospective adjunct faculty in addition to existing ones. Usage data collected for a one-year period after launching indicate the website was viewed 2,847 times from unique IP addresses. Each visit consisted of an average of 2 clicks per visit. More user data about these new online resources was obtained from our post-survey of adjuncts and is reported in Phase 3, below.

2. Adjunct-specific professional development programming. In response to the needs assessment theme of "isolation and disconnectedness," we felt it important to supplement the online resources with face-to-face programming exclusively for adjunct faculty. We chose faculty learning communities (FLCs) as a vehicle for building adjunct community because of their flexibility and proven track record in the faculty development literature. Cox (2004) defines a Faculty Learning Community (FLC) as a form of professional development that brings together cross-disciplinary groups of professors to engage over a period of time in an active and collaborative program focused on building a sense of community and enhancing teaching and learning. Faculty Learning Communities have become a popular method for improving teaching and learning as well as for promoting the professional success of faculty at all levels (e.g., Herrelko, 2016). Cox identified two basic forms of FLCs - cohort-based and topic-based. A cohort-based FLC consists of a group of faculty who share a common characteristic, need, challenge, or goal, and is more likely to be sustained over time and to focus on developmental needs of its members. Thirty years of studies offer definitive evidence supporting the use of cohort-based FLCs to promote the success of tenure-track professors (Cox, 2013) and more limited research has shown promising potential of FLCs with adjunct faculty (Buch \& McCullough, 2016; Lambert \& Cox, 2007).

The first adjunct FLC cohort was implemented at the beginning of the academic year following the adjunct needs assessment with 15 diverse faculty members who received a modest stipend for their participation. Since then, the program has evolved from a year-long to a semester-long program and has served 84 adjunct faculty. FLC program popularity has been so great that we have gone from one to two concurrent cohorts per semester, each consisting of 15 adjuncts facilitated by a separate CTL staff member. FLC members are selected through an application process on a first-serve basis, and every semester each FLC fills quickly and we have a wait-list. Each FLC session consists of two parts, each designed in direct response to needs assessment findings. The first half of each session is for community-building and consists of facilitated discussions about topics of relevance to adjuncts at our institution. The second half responds to the expressed need for more pedagogical/instructional support, and consists of 
a choice of two teaching workshops delivered by CTL faculty or staff. In a pilot program evaluation, FLC participants reported positive effects on teaching effectiveness and professional satisfaction (Buch \& McCullough, 2016).

Our inability to meet the demand for the FLC program led to our second face-toface program, a book club for adjuncts. Faculty who applied for but were unable to be accommodated in the FLC were encouraged to attend the book club, which was held at the same time on Friday mornings once a month during the academic year. The first book club book was the same one used by the first FLC cohort (Grieve \& Lesko, 2011) and all adjunct faculty were invited to attend on a drop-in basis (in contrast to the monthly commitment required of FLC participants). The book club was facilitated by a former CTL faculty fellow and university teaching award winner. Marketing for the club included direct emails to all adjunct faculty and digital signage in prominent places on campus. During the first academic year, attendance averaged 5-10 adjuncts per session, and this declined during its second year. We did not offer a book club exclusively for adjuncts this past semester, but instead encouraged adjuncts to participate in one of the book clubs offered by CTL to the entire faculty and staff. Our post-survey, as reported below, indicates that this was our least utilized adjunct initiative but anecdotal evidence suggests that adjunct faculty participate in the full-faculty book clubs at rates higher than tenure-track faculty.

Phase 3: Adjunct Post-Survey. A follow-up survey was sent to all adjunct faculty members 5 semesters (2.5 academic years) after the needs assessment reported in Phase 1 above. The survey was completed by 111 of the 319 adjunct faculty employed at the time of the survey, a 35\% response rate. Both the pre and postsurveys were completely anonymous and the adjunct population had of course changed, so there was no way to match respondents on the two surveys. The survey methodology was the same as the first survey, but most survey items were changed from an open-ended format to a check-list format consisting of responses obtained from the first survey. Item 1 listed the four adjunct initiatives (described in Phase 2 above) by name and asked respondents to check all they were "aware of" and a second item asked them to check all they had "participated in or utilized."

The next two items listed 11 specific types of support (formal and informal) reported by adjuncts in the needs assessment survey and asked respondents to check all that they "Do/Did" receive in their adjunct role (see Table 3 for list of supports). There was a twelfth option stating "NONE - I did not receive any type of formal or informal supports" as well as a space to write in additional (unlisted) supports they may have received. A fourth item provided the same list of supports and a space to write in additional ones that they "did not receive but would find beneficial" in their adjunct role. Item 5 was an open-ended question asking for "major challenges facing adjunct in your unit." The final open-ended item solicited additional "input toward the goal of adjunct support and development." 


\section{Results}

The first four items were tabulated as percentages and are reported in Tables 2 and 3. Results revealed that both awareness levels and participation rates among adjuncts are encouraging: $62 \%$ of respondents have utilized or participated in at least one adjunct initiative and many of these have participated in more than one program. The most popular program is the FLC, which almost a third have participated in. Almost half of respondents have utilized at least one of our online resources. This number may not reflect true usage rates for our target audience (new adjuncts) since our respondents may disproportionately represent more seasoned faculty who no longer have a need for an orientation and may have fewer questions that can be answered on the website. Less encouraging is that about a quarter of respondents were not aware of any of our new initiatives, indicating that we may need to step up our marketing efforts. There was a relatively small gap between awareness of and participation in the FLC (44\% aware and 31\% participated), suggesting that faculty who know about it are likely to participate in it (written comments indicated that several had applied but had not yet been accepted).

Table 2. Post-Survey Responses to Adjunct Initiatives

\begin{tabular}{|lll|} 
& $\begin{array}{l}\text { Aware of } \\
\text { Initiative/ } \\
\text { Resource }\end{array}$ & $\begin{array}{l}\text { Participated } \\
\text { in/ Utilized }\end{array}$ \\
\hline $\begin{array}{l}\text { Adjuncts Website } \\
\text { Online Orientation }\end{array}$ & 32 & 23 \\
\hline $\begin{array}{l}\text { Faculty Learning Community } \\
\text { (FLC) }\end{array}$ & 41 & 24 \\
\hline Book Club for Adjuncts & 44 & 31 \\
\hline None & 21 & 1 \\
\hline
\end{tabular}

Table 3 identifies the types of "formal and informal supports" received by respondents, as well as those not received that they would find beneficial. The most compelling finding is that only one respondent (.9\%) reported NO support, a huge improvement over the $25 \%$ reporting an absence of support in the needs assessment. Another change from pre to post-survey is the types of supports most frequently received; in the pre-survey the most common was administrative support while in the post-survey more received instructional support than administrative support. This finding reflected intentional efforts to center all adjunct initiatives around their core work activity - teaching. The only other types of support received by more than half of respondents in the postsurvey were: 1) receipt of communications, 2) administrative support, and 3) contact with colleagues and opportunities to collaborate. Direct comparisons of the two surveys cannot be made because the pre-survey solicited this information with open responses while the post-survey listed items identified in the pre-survey and could more easily be quantified. 
Table 3. Post-Survey Responses to Formal and Informal Supports

\begin{tabular}{|c|c|c|}
\hline & Received & $\begin{array}{l}\text { Not received but } \\
\text { beneficial }\end{array}$ \\
\hline Administrative Support (typing, copies, etc.) & 59 & 21 \\
\hline Adjunct Orientation & 39 & 16 \\
\hline Instructional Support (course syllabi, advice, etc.) & 61 & 14 \\
\hline Communications (on events and opportunities) & 57 & 10 \\
\hline Formal Mentoring & 22 & 26 \\
\hline Inclusion in unit business/operations & 31 & 15 \\
\hline Inclusion in instructional decision making & 21 & 20 \\
\hline $\begin{array}{l}\text { Contact with colleagues and collaboration } \\
\text { opportunities }\end{array}$ & 51 & 25 \\
\hline Referrals to useful resources/opportunities on campus & 29 & 24 \\
\hline Professional development by college/department & 15 & 23 \\
\hline $\begin{array}{l}\text { Professional development by CTL (Center for Teaching } \\
\text { \& Learning) }\end{array}$ & 40 & 12 \\
\hline $\begin{array}{l}\text { Other (write in) Peer Teaching Observation and } \\
\text { Feedback }\end{array}$ & 36 & 22 \\
\hline Opportunity to observe others teaching & 0 & 1 \\
\hline Graduate Assistants & 0 & 1 \\
\hline
\end{tabular}

Post-survey responses reveal that over a third of respondents did not check any items as "beneficial but not received," which, when taken with the write-in comments to the last open-ended item, may indicate satisfaction with available adjunct supports (see Table 5 for item 5 response summary). Of the listed supports, those endorsed the most as "beneficial but not received" include (in order of frequency): formal mentoring, contact with colleagues and opportunities to collaborate, referrals to useful resources, and professional development by college/department. Clearly, given the many adjuncts reporting receipt of these same supports, it can be extrapolated that delivery of these supports varies across units and that some units are better at referrals and collaboration than others. Two colleges have formal mentoring programs and professional development for adjuncts and these results suggest that adjunct faculty from the other five colleges would benefit from similar programs. Of the write-in supports ranked as not received but beneficial, peer observation of teaching was listed the most frequently.

The open-ended item asking adjuncts to list the major challenges they face in their adjunct role were content analyzed and revealed the following themes, in order of endorsements: 1) no challenges listed, or "none" reported; 2) poor pay and benefits; 3) isolation and disconnectedness; 4) lack of job security; and 5) lack of on-campus space to work and meet with students. Table 4 shows these challenges and how they differ from those reported in the needs assessment. Most notably is the sharp decline in adjuncts reporting a sense of isolation- 
dropping from $32 \%$ to $7 \%$. Another notable decline is the percentage of adjuncts either not reporting any challenges or reporting "none," dropping from $11 \%$ to $33 \%$. Other challenges showed little change from pre to post-surveys, although the frequency of these was relatively low.

Table 4. Major Challenges Facing Adjuncts: Pre and Post Surveys

\begin{tabular}{lll|l}
\hline \multicolumn{2}{l}{ Themes } & Pre & Post \\
\hline 1. No challenges faced & $11 \%$ & $33 \%$ \\
\hline 2. Isolation and Disconnectedness & $32 \%$ & $7 \%$ \\
\hline 3. Poor Pay and Benefits & $10 \%$ & $12 \%$ \\
\hline 4. Lack of Job Security & $6 \%$ & $8 \%$ \\
\hline $\begin{array}{l}\text { 5. Lack of Campus Space to Work and Meet with } \\
\text { Students }\end{array}$ & $5 \%$ & $5 \%$ \\
\hline
\end{tabular}

The final post-survey item asking respondents for open-ended "input toward our goal of adjunct support and development" were content analyzed and themes are reported in Table 5. One encouraging theme was that many adjuncts reported satisfaction with current levels of support and appreciation for the new adjunct-specific initiatives. Two additional themes (see Table 5) reflected adjuncts' desire for a continuation and expansion of formal adjunct-specific programming, as well as the provision of more informal campus-wide adjunct supports, including a forum for adjuncts to communicate with each other, more opportunities to meet and interact with other adjuncts, centrally-shared dedicated work/ meeting space for adjuncts, and a one-day adjunct conference, perhaps including adjuncts form other area institutions. A final theme was labeled "structural changes to adjunct faculty role" which was comprised of issues also mentioned in Table 4, such as poor pay and the lack of benefits and yearly contracts. The low percentages of respondents mentioning structural issues like these in either survey is likely related to the purpose and source of the surveys. Both surveys were sent from the CTL, and both were clearly focused on soliciting input about professional development rather than structural issues.

Overall, results of our longitudinal study provided strong support for the success of our institution's adjunct-specific resources and professional development programming, and also identified new opportunities to improve institutional support for adjunct faculty.

Table 5. Post-Survey Write-in Comments: What other input do you have toward our goal of adjunct support and development?

Themes and Illustrative Quotes

1. Satisfied with Current Support

"I am satisfied with the support I receive"

"I participated in the adjunct FLC and found it extremely beneficial"

"I am supported and valued by my department"

"I am very happy with what's offered"

2. More Formal Adjunct-specific Programming 
"More online opportunities through CTL"

"Summer Canvas (LMS) course for adjuncts"

"More professional development geared specifically to adjuncts"

"Ability to take existing courses online/ virtually"

3. Informal Campus-wide Adjunct Support

"Forum for adjuncts to communicate with each other"

"Monthly meetings with other adjuncts"

"Social events/ opportunities to meet other adjuncts"

"Brown-bag lunches for adjuncts"

4. Structural Changes to Adjunct Faculty Role

"Need yearly contracts"

"Living wage"

"Health Benefits"

"Transition assistance to full-time roles"

\section{Discussion}

We began this paper with several important questions about adjunct faculty that our findings have helped elucidate. Can targeted resources and professional development opportunities meet the unique needs and challenges of adjunct faculty? How do adjunct faculty respond to institutional efforts to deliver targeted resources and programming? Our needs assessment found that adjunct-specific online resources and face-to-face programming were desired by adjuncts and our post-survey found that these offerings were widely embraced, with about two-thirds of responding adjuncts utilizing or participating in at least one. Our study also found that increased attention to the unique needs of adjunct faculty can enhance adjunct faculty's perceptions of their level of institutional support, both formal and informal. We also observed that the provision of targeted resources and programming in direct response to adjuncts' voiced needs can alleviate major challenges such as feelings of isolation and disconnectedness.

There are some clear implications of this study for our own as well as for other institutions. First, as reported in the literature (e.g., Forbes, Hickey, \& White, 2010; Kezar, 2012; Meixner \& Kruck, 2010) and discussed above, adjunct faculty are different from full-time faculty and have unique needs and challenges. Institutions should respond with tailored professional development opportunities, targeted resources, and a range of formal and informal supports. While there are some cross-institutional trends in needs and challenges - both professional development and structural-each campus should begin with its own needs assessment which should drive all subsequent adjunct initiatives.

Once adjunct initiatives have been implemented, it is important to track both awareness and participation levels and to continue to monitor changing adjunct needs and perceptions. We are already using our data to make changes to existing resources and programs and to identify directions for future programming. For instance, this study identified several promising directions for future programming and support, including an expansion of the peer observation program that is currently isolated in one college, as well as the 
provision of more unit-specific (department or college) professional development opportunities to supplement the institutional initiatives reported here. Respondents in the post-survey made some suggestions for innovative adjunct support that we in the CTL had never even considered, such as the adjunct-specific conference and the shared adjunct commons. Other suggestions reinforced some ideas we had been discussing, such as professional development credits (e.g. badges), prize drawings, or other tangible incentives for participation besides stipends. Our findings also identified ways to improve the assessment process itself in order to better understand which specific groups of adjunct faculty we are serving and which are not being reached, and why which in turn will allow us to refine and improve our initiatives.

While our findings offered support for our research-guided approach to supporting adjunct faculty, it is important to acknowledge that our successes are limited and that there is still much work to do. In spite of serious campus-wide communication efforts during the past five semesters, a quarter of adjuncts responding to our post-survey were unaware of any adjunct-specific resources or opportunities. And even though we tried to incorporate adjuncts' input from the needs assessment in our design and delivery, we still have not reached over a third of responding adjuncts with any of our initiatives. Finally, our professional development initiatives have not-and cannot-address some of the major issues and challenges facing adjunct faculty on our campus and across the nation. These are structural issues of inequity in pay, benefits, upward mobility, and job insecurity for adjunct faculty in relation to tenure-track faculty. Not only is it an ethical imperative to begin a dialogue around these difficult inequities, it is also vital to the instructional mission of the university for many reasons.

First, as already stated, faculty working conditions are student learning conditions, and student learning is clearly impacted when faculty are not provided with the support and resources needed to be effective teachers. Second, adjunct faculty have been shown to be dedicated, competent, hardworking professionals committed to the success of their students and eager for community with their colleagues (e.g., Kezar \& Sam, 2010; Webb, Wong, \& Hubball, 2013). Failure to provide working conditions that will retain this workforce can lead to higher rates of turnover in an increasingly tight labor market (Flaherty, 2017). Inviting open dialogue about structural inequities can also help build a climate of trust and collaboration for adjunct faculty while raising awareness among tenure-track faculty, many of whom are unaware of the implications of a two-tier faculty system for adjunct faculty or students. Finally, those involved in centers for teaching and learning, faculty mentoring programs, and other forms of faculty development and support must realize that failure to acknowledge and confront structural issues can undermine or negate even the most well-intentioned and effective professional development initiatives. 


\section{References}

AAUP (American Association of University Professors, (2013), Contingent Appointments and the Academic Profession. Retrieved from http://www.aaup.org/report

Buch, K., \& McCullough, H. (2016). Addressing the needs of adjunct faculty with a cohort-based faculty learning community. Learning Communities Journal, 8(1), 3550 .

Cox, M. D. (2004). Introduction to faculty learning communities. In M. D. Cox \& L. Richlin (Eds.), Building faculty learning communities (pp. 5-23). New Directions for Teaching and Learning, No. 97. San Francisco: Jossey-Bass.

Cox, M. D. (2013). The impact of communities of practice in support of early-career academics. International Journal for Academic Development, 18(1), 18-30. doi: 10.1080/1360144X.2011.599600

Fagan-Wilen, R., Springer, D. W., Ambrosino, B., \& White, B. W. (2007). The support of adjunct faculty: An academic imperative. Social Work Education, 25, 1, 39-51. doi: 10.1080/02615470500477870

Flaherty, C. (2017). Youngstown State adjuncts celebrate 25 years without a raise. Inside Higher Ed, February 22, 2017.Retrieved from https://www.insidehighered.com/news/20137

Forbes, M. O., Hickey, M. T., \& White, J. (2010). Adjunct faculty development: Reported needs and innovative solutions. Journal of Professional Nursing, 26(2), 116-124. Doi: 10.1016/j.profnurs.2009.08.001

Gappa, J. M., \& Leslie, D. W., (1993). The invisible faculty: Improving the status of part-time faculty in higher education. San Francisco: Jossey-Bass.

Grieve, D., \& Lesko, P. (2011). A handbook for adjunct/ part-time faculty and teachers of adults (7th Edition). Ann-Arbor, MI: The Part-Time Press.

Herrelko, J. M. (2016). How learning community guidelines impacted a mathematics professional learning community. International Journal of Learning, Teaching, and Educational Research, 15, 11, 111-127.

Hoyt, J. E. (2012). Predicting the satisfaction and loyalty of adjunct faculty. The Journal of Continuing Higher Education, 60(3), 132-142. doi:10.1080/07377363.2013.722417

Kezar, A. (2012). Spanning the great divide between tenure-track and non-tenure-track faculty. Change, http://www.change.org/se/util/display

Kezar, A. \& Sam, C. (2010). Special Issue: Non-tenure-track faculty in higher education: Theories and Tensions. ASHE Higher Education Report, 36, 5, 1-91.

Kezar, A., \& Maxey, D. (2014). Troubling ethical lapses: The treatment of contingent faculty. Change, July/ August, 34-37. Doi: 10.1080/00091381.2014.925761

Kingkade, T. (2013). Faculty pay survey shows growing gap between public, private colleges. The Huffington Post, 4/8/2013.

Lambert, H. E., \& Cox, M. D. (2007). The two-year effort to build a program that provides part-time faculty pedagogical support, community, and a sense of mission. In R. E. Lyons (Ed.), Best practices for supporting adjunct faculty. Bolton, MA: Anker.

Levin, J.S. \& Hernandez, V.M. (2014). Divided identity: Part-time faculty in public colleges and universities. The Review of Higher Education, 37, 4, 531-557. doi: 10.1353/rhe.2014.0033.

Meixner, C. \& Kruck, S.E. (2010). Inclusion of part-time faculty for the benefit of faculty and students. College Teaching, 58, 141-147. doi:10.1080/87567555.2010.484032

New Faculty Majority (2015). Retrieved from http://www.newfacultymajority.info/equity/

Webb, A. S., Wong, T. J., \& Hubball, H.T. (2013). Professional development for adjunct teaching faculty in a research-intensive university: Engaging in scholarly approaches to teaching and learning. International Journal of Teaching and Learning in Higher Education, 25(2), 231-238. 